\title{
N84 10169
}

AFFTC OVERVIEW OF ORBITER-REENTRY

FLIGHT-TEST RESLLTS

Robert $G$. Hoey

A1r Force Flight Test Center

Edwards Alr Force Base, California

INTRODUCTION

The Air Force Flight Test Center (AFFTC) has been participating in the flight he Space Shuttle since 1976. We were tasked by Space Divis:on to conependent assessment of the reentry and landing capabilities of the uct an independent assessment of the reeftre (DOD) mssions. Th:s activity is rbiter with respect to Department of n-going aho reports have been published after each assessment activity, however, hi: conference is not directly related to the technical

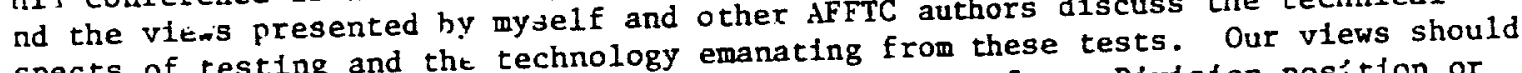
spects of testing and the technology efial Air Force or Space Division position or ot be construed as representing offelat of the "testers".

\section{ABBREVIATIONS AND SYMBOLS}

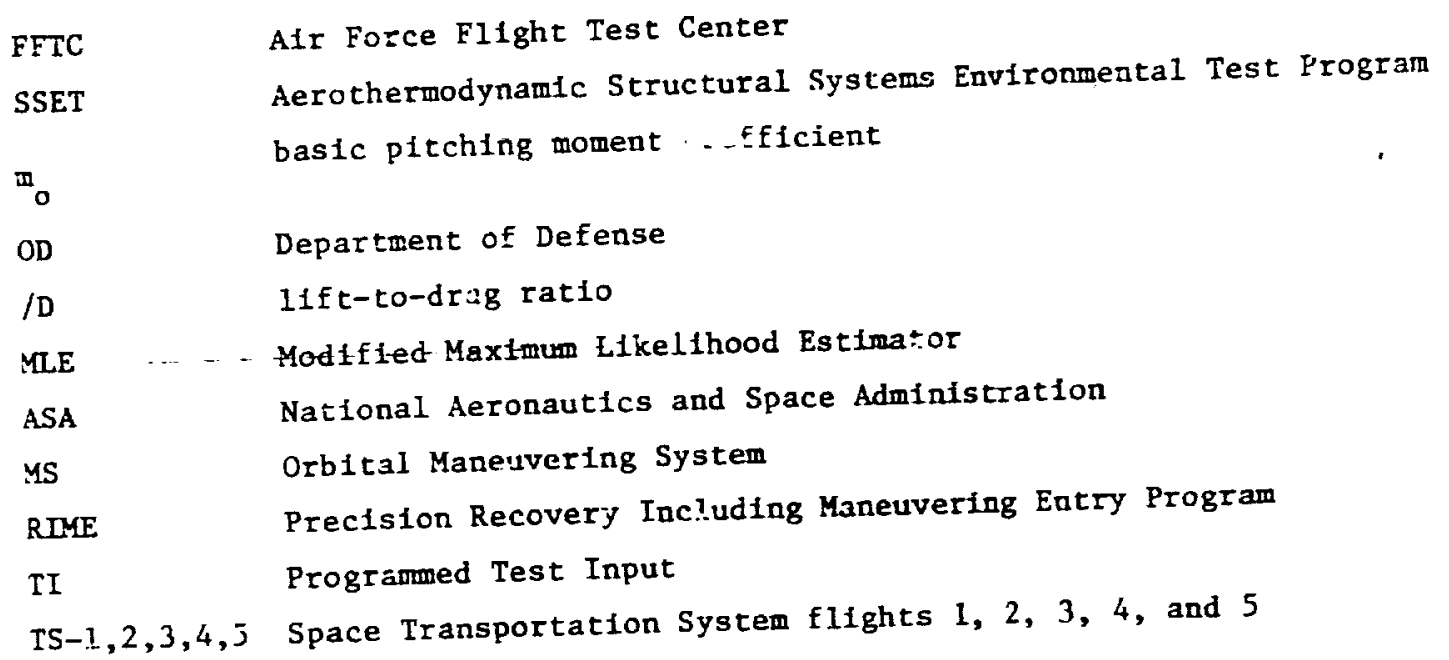

\section{BACKGROUND}

The Air Force has been Interested in hypersonlc Elight and maneuvering reentry or many years, primarily spearheaded by efforts of the Air F́rce Flight Dunamics abcratory (now Alr Force Wright Aeronautical Laboratory) (Figure 1 ). In the late 
i950's, the X-15 program was inttiated by a joint DOD/NASA team, funded priaariig by the Air Jorce. This progran has been recognized as the most successful of all o: the X-sezies research alrcraft, breaking new ground la many areas of hypersonic Elight and lifting reentry. The follow-on program, the X-20A DynaSoar, was cancelied bejore fligit jut resulted in many development activities which were cec=solog advances: for example, a triply redundant, self-adaptive, fly-by-uire flight zcatrol system. The Air Eorce Aercheroodynamic Structural Systems Environmental Test (AS'SET) and Preciston Recovery Including Maneuvering Entry (PRIME) programs, bot: small, uzanned lizting resatry shapes, were flown in 1963 and 1966 , respectively. These teses successfuily demonstrated both radiative/metallic and ablative thersal protectica system concepts. The lifting body programs $(\mathrm{M}-2, \mathrm{HL}-10, \mathrm{X}-24 \mathrm{~A})$ explored zransonic aecodynazics and Ianding characteristics of Low Iift-to-drag ratio (L/D) zeentry conflguration. The AIr Force $X-24 B$, the las of the $X$-sertes rocket-posered zesearch rehicles, was repzesentative of high hypersonic i/D configurations ard zerforted the first hard-surface rumay landing for veicicles of this class.

The zany years of preparation zepresented by these programs have produced preifction echniques for the Jesign of lifting reentry vehicles. The Space Shuttie orbiter represants the culmination of all of this activity comblned with the tecilology from the "capsule" programs. During this conference you have heard how well Lhese prediction techpiques worked. Some were accurate, some too conservative, and some non-conservative.

This paper touches on Elight test results from must of the technical disciplines and attemes to relate them to each other with regard to the design of future $1 \mathrm{f}=t i n g$ zeentry rehicles. Performance (1.e., aerodyanmic lift and drag), stability and conrol, aercdynamlc heating and thermal proteciton, and unpowered approach and landing are the technical areas where te think major technology advances are being made.

\section{PERFORMANCE}

The $I / D$ of the 0 bite was predicted very well over most of the Mach range IEigure 2;. Although all extries have fellowed a 40 degree angle of attack profile, ransfent pushover-ovilup maneuvers have produced accurate trends with ingle of Ettack. Ine subscic I/D was underpredicted somewhat cue to a conservative estizate of the efjects of $:$ ie surface roughness on drag. Since aerodynamic $L / D$ is the prime reasure $c$ reentry laxeutering capability, the Crbiter guldance and energy management control Iers have wrked we 11 and entry trajectories have been very close to nominal. IIthough the ratio of Iift to arag was well precilcted, the magnitude of the normal Force coefficient $C_{N}$, which is the prime contributor to both lift and drag at high ingle of attack, was overpradicted as shown on the right side of Figure 3 . The cause af this discrepancy is not rell understood at this time and efforts to resolve the iffezences are haupered by 3 lack of accurate, onboard measicements of dynamic pressure at the high Mach numbers $x$. In addition, abrupt changes in measured accelera=̇ons (up to 19 perceat over a one second time period) have been recorded which do sot appear to correspord to flow changes over the vehicle. Changes in atmospheric jecslty a:z currenty consizered the rost $11 \mathrm{kely}$ cause for these anomalies and, if zandom in sature, sould be an important design consideration for future vehicles and sildance concests. 
A signiflcant discrepancy in pitch trio pretictions jas been observed on all ghts (Figure 4). Elevon fulses, bodyflap sweeps, and ₹ushover-pullup maneuvers 'e Isoiated the individual pitching moment contributions from the elevon, bodyIp, ard angle of attack and determined that they are all close to predictions. ' trim prediction error has thus been isolated to $C_{w_{0}}$. Becent theoretical compuilcns by personne? at the Arnold Engineering Developmen= Center jave attributed the icrepancy to real gas effects. The magnitude of the corfection is quite large and -trays the heavg relfance that rust be placed on theoresical an 1 computational codynamic models jor the design of future reentry vehtcies. Had this informaticn in avallable soczer the nose ramp angle on the Orbiter could have been reduced Ightly wht th would have brought the bodyflap and elevor zack to the desired ired position. The result would have been lower temperatures in both the nose ip area and the control surfaces.

\section{STABILITY AND COSTROL}

Stabillty and control derivatives have been extracted from flight test maneuvers rformed over most of the current reentry flight envelope. For the most part the close to jredictions, although small discrepancies are seer in nearly rivatives arfivatives. A notable exception is the prediction of yan jet interaction 1 of the derivatives the initlal phase of reentry (Figure 5). The jet interaction effects fects diring the lnitlal phase of reentro townaric pressures $\bar{q}$. The conseroll were much swaller than predicted at the 1ow dyate ather large, slow, lateralence of this prediction error is shown on Flgank maneurer of the STS-1 entry. A rectional osciliation occurred on the first bank mached doring the oscillation commentary sideslip angle of over 4 degrees was reached doring the teparicy was again a red to a prediction oi about 1 degree. Ihls predsctig duplicate the simultaneous sult of Inadequate ground test facilities co accuratent. Orbiter flight test data gh Mach number, low density, rocket fouluable in laproving our ability to preflct $t$ interaction effects in the future.

The long dashed IInes on Figure 5 also portray the se oi derivat"ve predicted ta uncertainties as used in the development of the Orbizer filght cuntrol system. constderable amount of effort was expended early in the prugram to estabilsh approlate uncertainty bounds arouñd each derivative predictson. These uncertainties re based on three factors: (1) differences between wid turels, (2) differences tween prediction and flight test results for a variety of aircraft, and (3) judgnt regarding the validity of extrapolations in Hach nuber. The Orbiter control stem was designed to accommodate individual wocertaintses in the derivatives as lown 57 the dashed 1 ines as well as certain logical cominations of urcertainties presenting worst-case condltions. The effort was we+l wortil the time expended. 1 of the derivarive prediction discrepancies wave beex rithis the variation bounds ccept for the case shown in Figure 5. As a result, the flight control systen has en adequate for safe reentry and landing approaches in elther the automatis or inual modes in spite of frediction errors. 
The lower surface or windward side of the Orbiter has experiencez a iess severe heating envirorment than expected (Figure 7). Three factors have comoined to create this situation. The laminar teating during the early portion of the entry has jeen less than predicted, espectally on the forjard portion of the vehtcle. The tratsition from laminar to turbulent flow has occurred later in the intry than expected witich has also produced lower temperatures and a lowez total heat loas. dizer the renicle passes througl, Mach 2.5 , vent doors open on the side of the Fiselage to savalize the pressire in the payload bay and other internal cocpartine=s. The Elow 0 cold air into the :ablele as weil as over the outslde surface was =ci accounzed for in tine conservative iloating models used in the design process. Fis atzospieric cooling effect is quite significant and causes inteinal structural temperatures to peak earlier and at lower value $=$ than anticlpated. The combination $c$ F these three effects has al.leviated concerr. over the overall adequacy of the lower surface design although several localized problems remain (tile gap heating, for example). The repeatability of these three effects needs to be considered. The reduced laminar heating appears to be repeatable. The transition from laminar to turiuleat flos bas been consistently later than expected but somewhat different for each ilizit. The mechanism for controlling flow transition needs to be better understocd berore a future design could confidently count on late transition in sizing the theral crothe Orbiter could be controlled testing of boundary layer transition pienorsia on che Orbiter could be very beneficlat to the design community. The atmospheric cooling effect has been, and should be, highly repeatable. The next ginerarion of entry vehicles might well be equipped, not only with vent doors, but with air scoops and Internal baffling to effectively utillze the three to five minutes of free cooling provided by the atmosphere while descending below $80,000 \equiv e e$.

The heating on the upper surface, or lee side, of the Orbiter has beet pcoriy predicted (Figure 8). This was not entirely unexpec ed since theory is essentially non-existent for complex shapes and wind tunnels cannot simultanously jupliface tie flow conditions of Mach and Reynolds number. Several localized areas jave Experlenced higher heating than predicted, In particular the Orbital Maneuvering system (OMS) pod, side of the fuselage and payload bay door. Wind tunnel date predicted that a vortex Impjngement would occur on the OMS pod abruftly as the argle of attack decreased through 30 degrees. Flight test rasuits to date Indicate an increase in heating starting at about 37 degrees angle of attack and building to considerably higier levels at lower angles of attack. The heating patterns and trends are reasonably repeatahle from flight to flight and aerothernodynamic math models for the OMS pod and several other upper surface locations are currently befag revised using the avallable flight test data base. Bere again, additional testing of the $0=b i t e r$ is required to thoroughly understand the factors wh $f$ ch influence upper surface heatirg and to establish better toois for predictions on future rehicles.

\section{FLIGHT TESTING TECHNIQUES}

derodynanic flight testing of the Orbiter during entry successflil- utilized aircraft dynamic testing techniques. (See fig. 9.) Slow pushover-pullups tere performed to sweep a range of angles of attack while the vehicle remained essentially in trimed flight. This maneuver and the corresponding analysis program has been 
used successfully on rocket powered glide vehicles for many years producing lift, drag, and longitudinal trim data as a function of angie of attack for a particular Mach number.

Proyramed Test Inputs (PTIs) were sharp control pulses destgned to momentarily upset the trimed equilibrium condition. The instrumentation then recorded the anner in which the inherent stability and the control system returned the vehicle to equilibrium flight. These maneuvers are similar to the stick pulses used in aircraft dynanlc stability testing. The Modified Maxiaum Likelthood Estimator (MME) analysis program has been in use for several years. It produces a set of valuss For the vehicle stability and control derivatives for each PTI test maneuver. The bodyflap sweep was used to isolate the bodyflap eizectiveness derivazive and thus establisn the overall pitch irim capabiliry of the orjiter.

The data from pushovier-puilup and bodyflap sweep maneuvers were analyzed by an entirely new technique for the dynamic testing of the aerothermodynacic tnvironmrat. Using tine trajectory data and the angle of attack tise history as inputs, the new program adjusts the heating model until the output temperature time history matches the the rmocouple readings as shown on Figure $10(\mathrm{a})$. The flight-adjusted heating rodel is compared with the wind tunnel data in Figure $10(\mathrm{~b})$. Excellent results of heating variation with angle of attack have been ottained for lowe: surface locations. Nonlinear heating varlations, such as on the OMS pod, have also been successfully identified but with lower confidence. Thermal math models for various critical locations are being updated with these flight test results. It is hoped that the aerothermodynamic flight testing techniques which were developed for the Space Shuttle program will form the basis for a whola new flignt test discipline which will be applicable to any hyperscnic aircraft or reentry vehtcle.

\section{UNPOWERED LANDINGS}

A piluting technique for landing a low $L / D$ glide vehtcle was developed in the $1350 . \geqslant \equiv 0^{\prime} s$ and early $1960^{\prime} \mathrm{s}$ and was successfully applied to lakebed landings of the $\mathrm{X}-1 \mathrm{~J}$ : Esearch aircraft. As confldence was gained in the abillty to successfuily ccar:s: is energy, spot landings were attempted with a fair degree of success. Ir $19: 0: \quad$ :t research program was conducted by AFSTC using an F-1ILA which succ.sur $\therefore$ - wnstrat =d a technique for accomplishing night and instrusent approaches. Severa: . . Jec low $\mathrm{L} / \mathrm{D}$ approacies were flown from Mach 2 down to 1500 feet altitude where a visual zlare and landing were completed. Typical landing patterns for the $X-15, X-24 B$, and Space Shuttle Orbicer are shown in Figure 11. The approach and landing technique were the same for each. An overhead, high altitude, circular pattern was flown followed by a high speed final approach (approximately $300 \mathrm{krots}$ ). A flare maneuver to essentially horizontal, deceleraing flight was inftiated at about 1500 feet alticude. The landing gear was exterded during or af:er flare and touchdown occurred between 160 and 200 knots. Notice the similarity in the fiual approach glide slope between the three vehicles which is indicative of the similarity in subsonic L/D. Notice also that as the landing technique evolved toward improved laxding accuracy, the geometry of the pattern was altered to include a longer inai approach. This resuits from the necessity to establish a stabllized energy level at the flare point in order to fropurly control the touchdoin point and stopping point. 
Aditiona: refinements to this landing technique are still being Eude, such as ituprovements in the ability to compensate for upper altitude rinds; however, the basic technique ror accomplishing unpowered, low L/D landings ias proven to be effective and practical.

\section{CONCILDING REW RXS}

The Sface Shutele test program has been highly successful by any stancard of Jeasur?. The rehicle wic designed to ily in an environcent which was largely unchar ied. Many cesign prediction tools were verified (see $=i z \cdot 12$ ). including a general verification of lifting entry destgn methods and confimation ci reusable thermal protecticin system tochuology. Aircraft flight testing technicues were successfi' $y$ applied and now aecothermodynamic flight testing teciniques Fere successEully aemonstrated.

sany of the design prediction tuols were found wanting, as shown in figure 13, b't the aprilication of a conservative design philosophy allowed the test. program to rroceed safily. For example, hypersonic pitch trim and normal force coefficients vere not well predicted. Jet intezaction eifects at low dynanic pressure were also zispredicted, Aercdynamic heating on the lower (windward) suriace was generaily lower than predictions while heating on local areas of the upper (lteward) surface was nigher than expected. It appears that future designers will have to rely more reavi:; on thecry and computational aercdynamics (or even empiricaj me $:$. is based on ilight test) to supplement the wird cuniels for the hypersonic exviror-i?t. (See Eig. 14.)

The five-flight test frograw of the orbiter has opeasd the foor t. severai tzchlological advances which could significantly impact the design of futui. hypersonic rehicles. It is essential that the nezessary test data be gathered on future Space ihuttie orbiter reentries to insure that this new technology is properly developed. 
$\begin{array}{lllllllll}1945 & 50 & 55 & 60 & 65 & 70 & 75 & 80 & 85\end{array}$

V-2 WHITE SANDS-

VIKING SPUTNIK

MERCURY

SPACECRAFT

GEMINT

CRIGISAL PAGE IS

OF POOR QUULITY

APOLC $\sigma$

SKYLAB

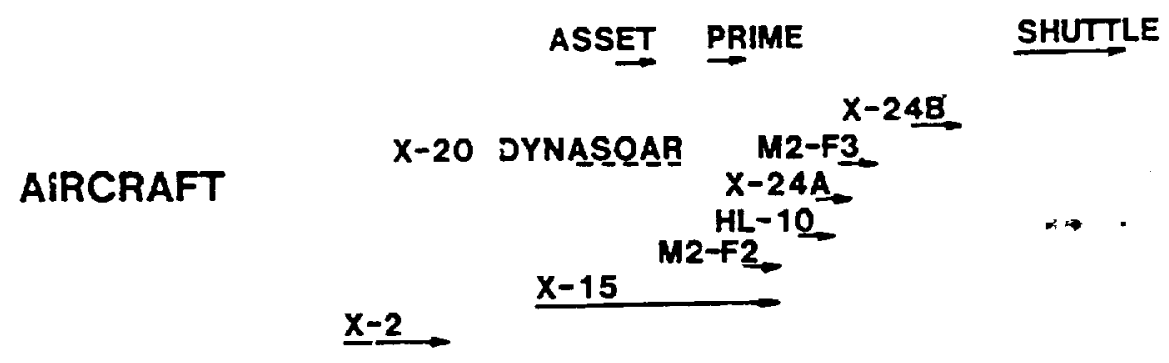

$X-1$ SERIES

Figure 1.- Chronology of spacecraft/atrcraft development.

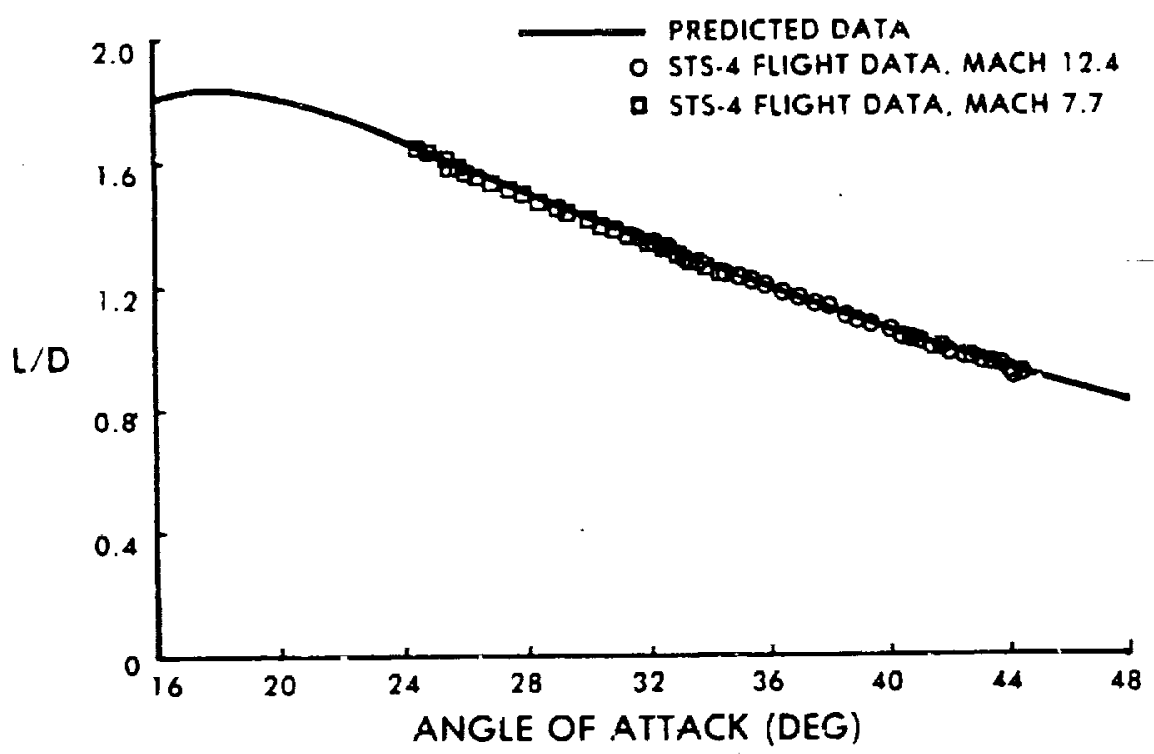

Figure 2.- Hypersonic lift-to-drag ratio data.

$$
c-8
$$


ORIGINAL PAGE IS

OF POOR QUALTYY.
PREDICTED DATA

PREDICTED DATA UNCERTAINTIES

○ FLIGHT DATA

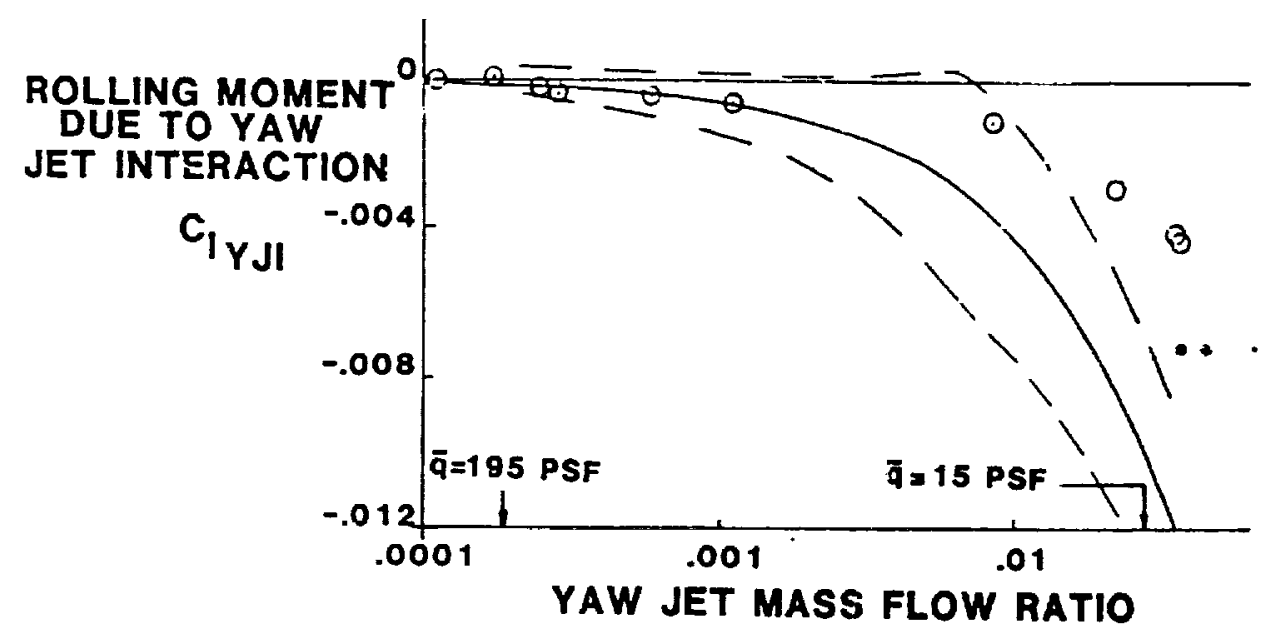

Figure 5.- Yaw jet/aerodynamic Interactlon.

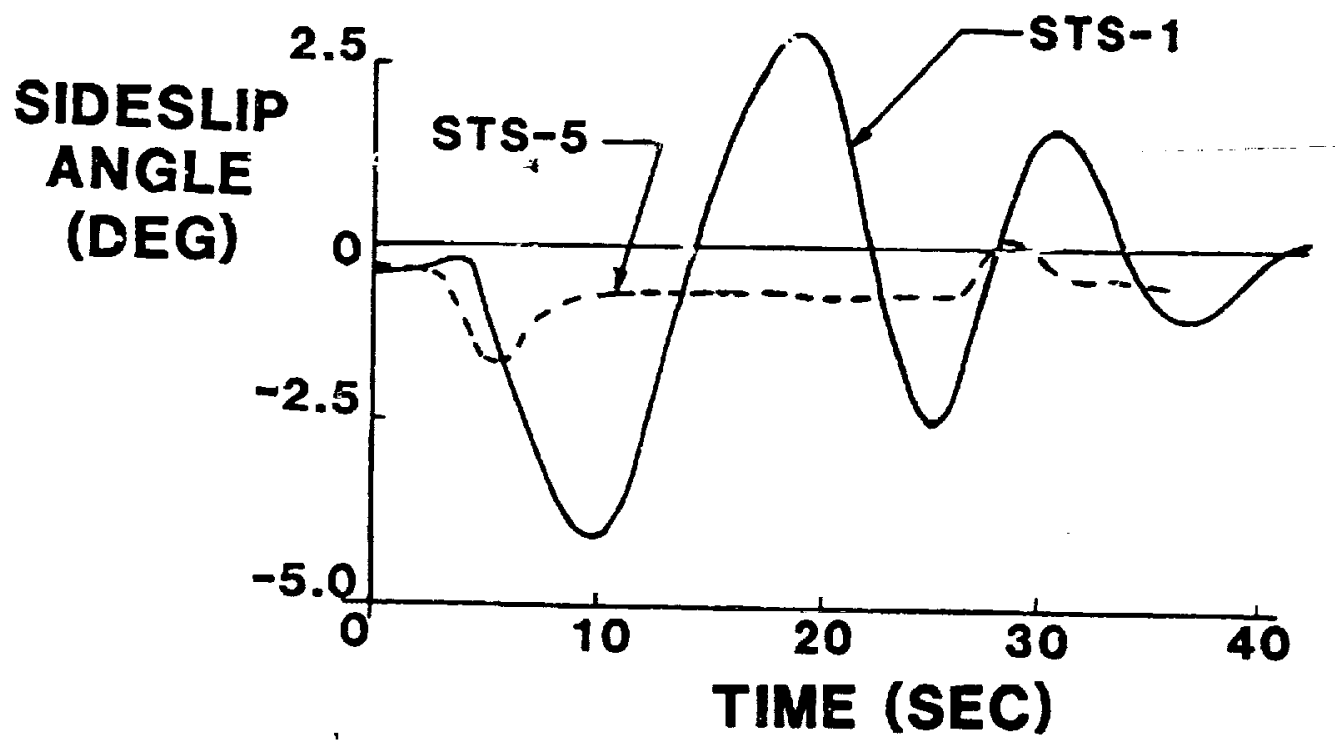

Figure 6.- First bank maneuver (auto). 


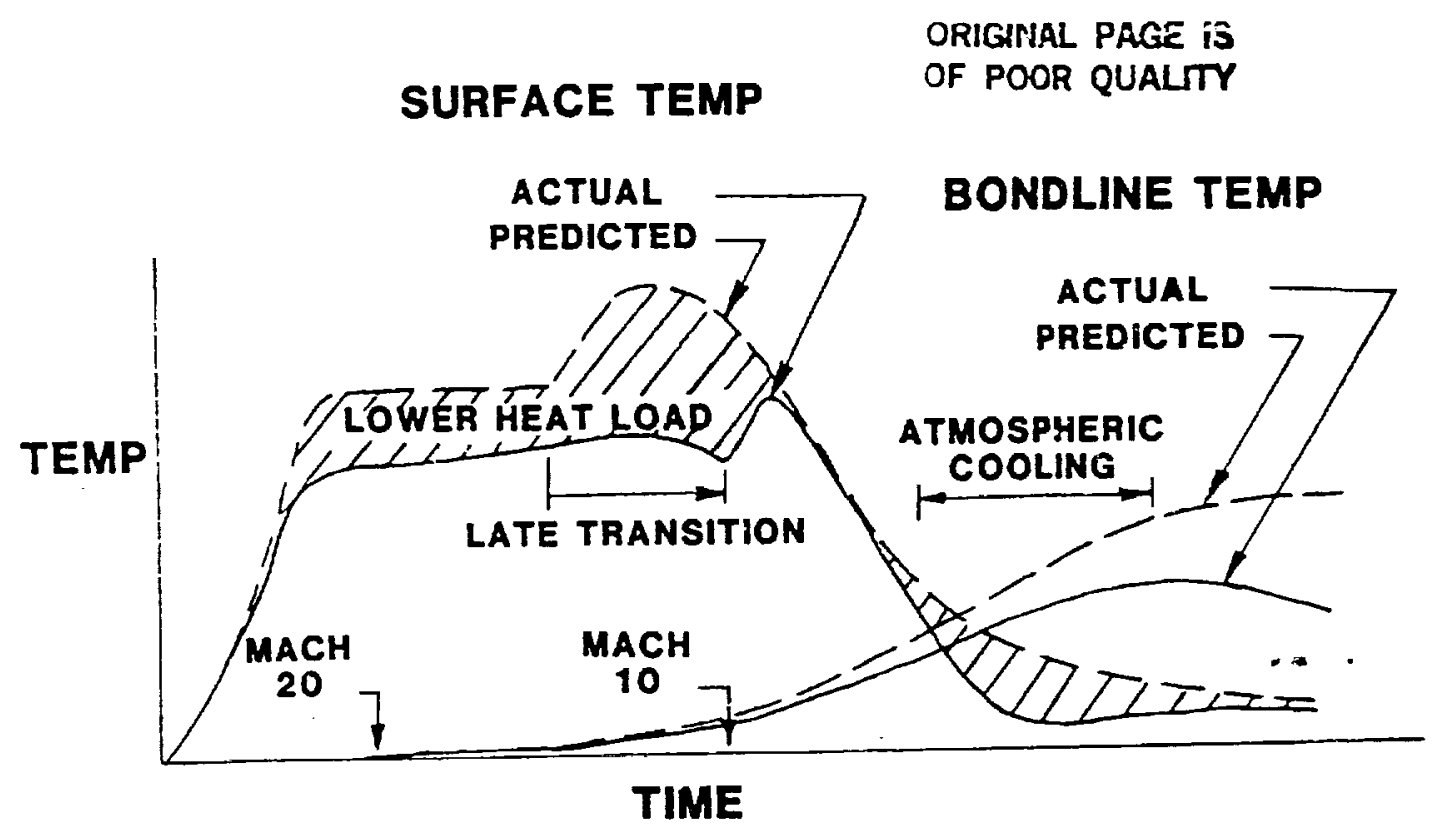

Figure 7.- Generalized lower surface heating results.

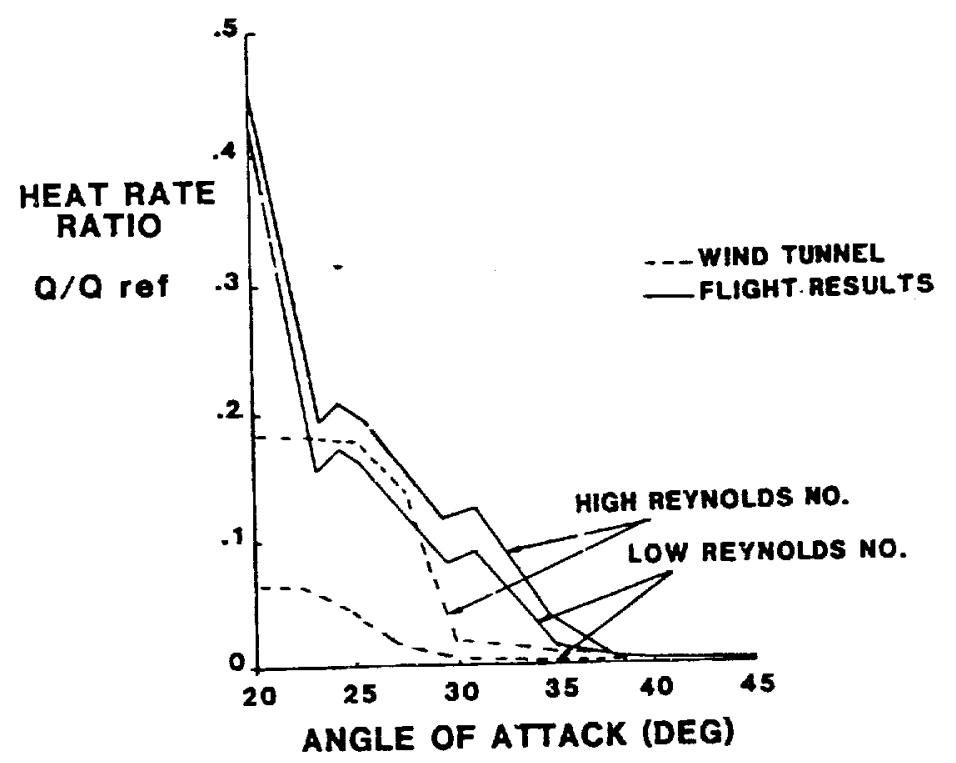

Figure 8.- oMS pod heating. 
MANEUVER

- SLOW PUSHOVER-PULLUP
- PROGRAMMED TEST INPUTS

(CONTROL PULSES)

- BODY FLAP SWEEPS
DATA OUTPUT

LIFT, DRAG VARIATION WITH ANGLE OF ATTACK NEW AEROTHERMODYNAMIC ANALYSIS

\section{STABILITY AND CONTROL DERIVATIVES}

BODY FLAP/ELEVON

EFFECTIVENESS

NEW AEROTHERMOCYNAMIC ANALYSIS

Figure 9.- Successful application of aircraft dynamic testing technicues. 
ORIGNAL PAGE 15

OF POOR QUALITY

... FLIGHT DATA

- REVISED HEATING MODEL

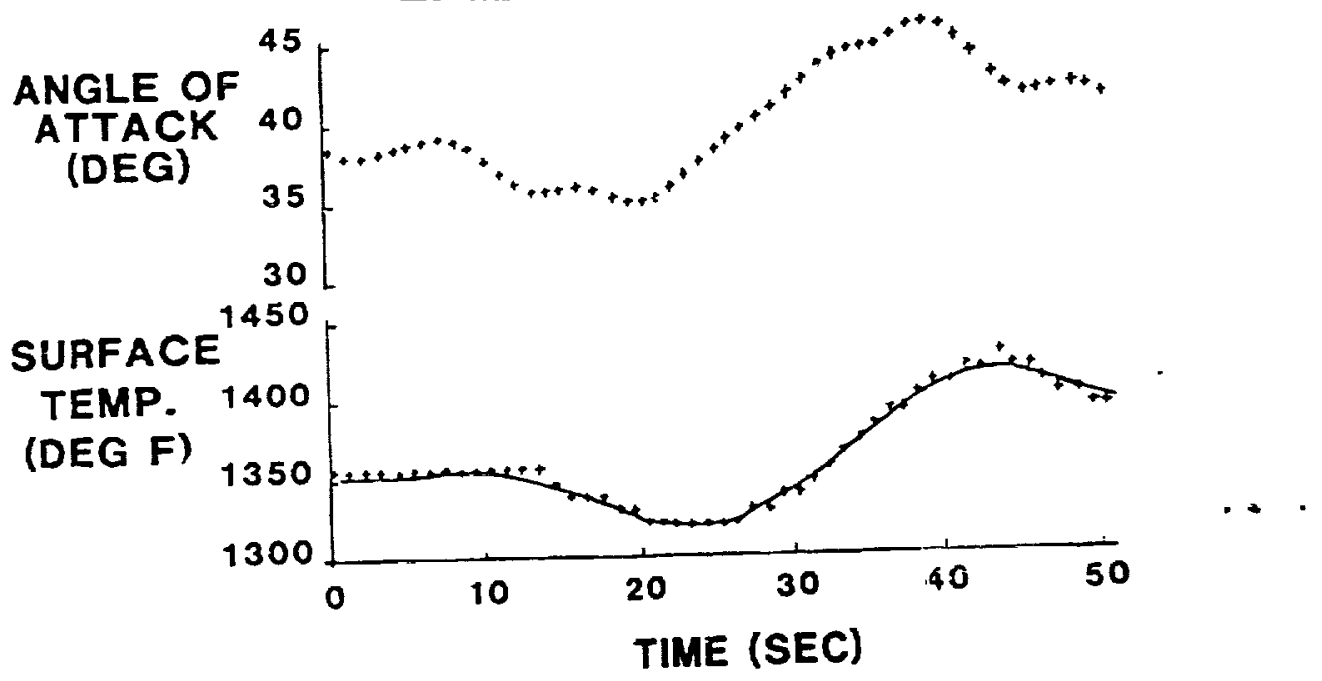

(a) Dynamic test waneuver for aerothermodynamics.

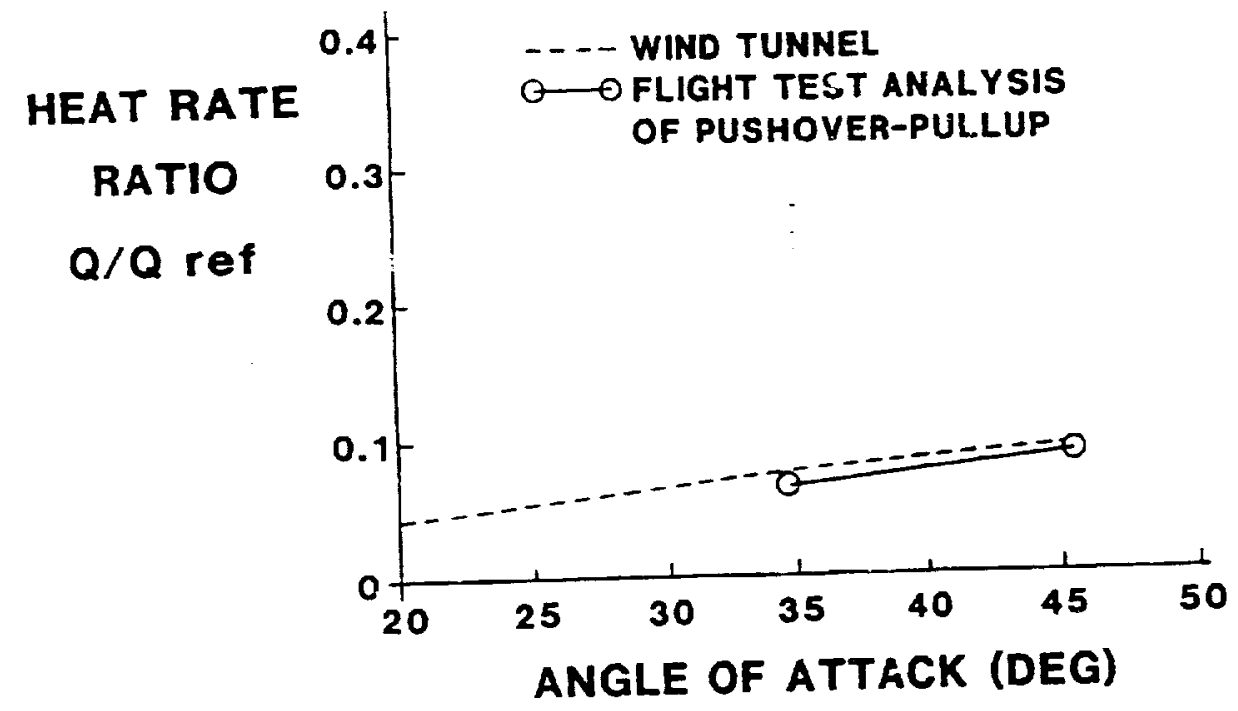

(b) Aerothermodynamic resi:lts from dynami= maneuver analysis.

Figure 10.- Dynamic testing of aerothermodyramic environment. Aft lower centerline. 

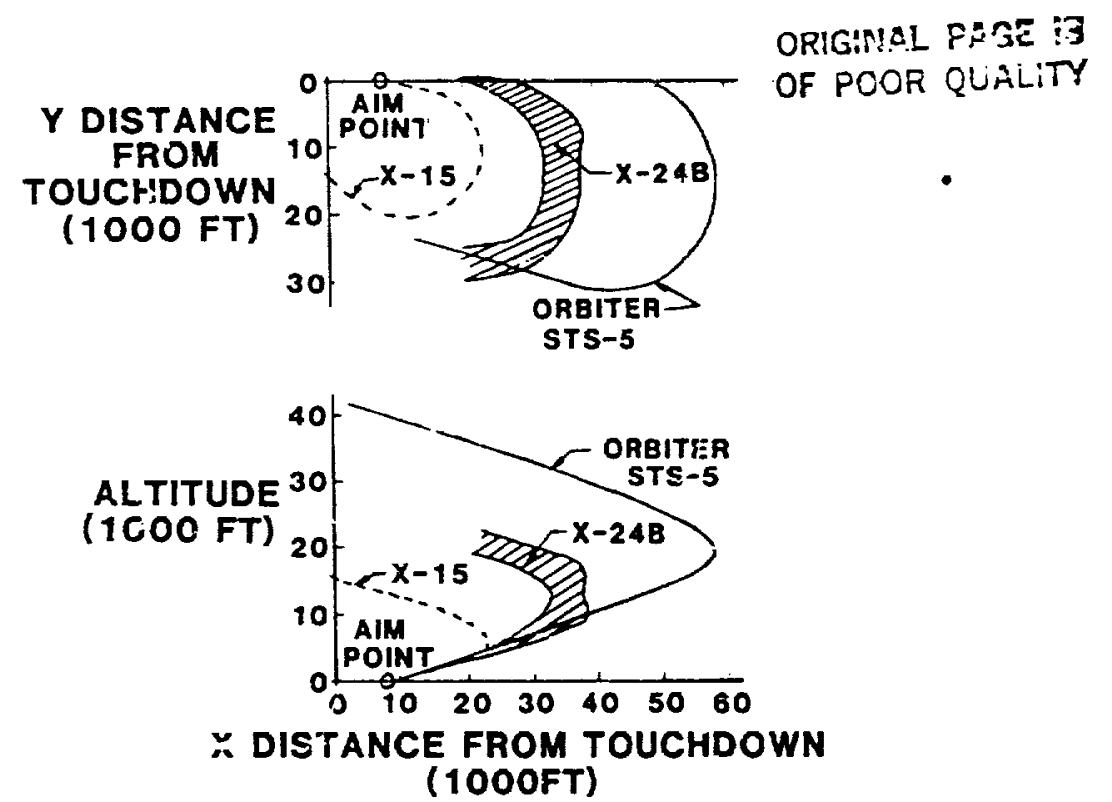

Figure 11.- Low L/D Janding patterns.

- OVERALL LIFTING ENTRY DESIGN METHODOLOGY

- REUSABLE THERMAL PROTECTION SYSTEM TECHNOLOGY

- APPLICATION OF AIR:RAFT TEST TECHNIQUES

- AEROTHERMODYNAMIC FLIGHT TEST METHODS

- UNPOWERED, LOW L/D LANDING TECHNIQUES

Figure 12.- Lessons learned. Design prediction methods verified. 
- HYPERSONIC PITCH TRIM AND NORMAL FORCE COEFFICIENTS

- JET INTERACTION EFFECTS

- LOWER SURFACE HEATING (OVERPREDICTED)

- UPPER SURFACE HEATING (LOCALLY UNDERPREDICTED). . .

- SUBSONIC LIFT-DRAG RATIO

Fłgure 13.- Lessons learned. Design prediction discrepancles.

- FUTURE HEAVIER RELIANCE ON

THEORY

COMPUTATIONAL AERODYNAMICS EMAPIRICAL FLIGHT TEST RESULTS

TO SUPPLEMENT WIND TUNNEL PREDICTIONS

- SIGNIFICANT TECHNOLOGY BENEFIT TO BE DERIVED FROM CONTINUED ORBITER REENTRY TESTING

Figure 14.- Concludin: remarks. 